\title{
The Chequered Career of a Cryptic Concept
}

\author{
CLAIRE DONOVAN
}

\section{Introduction}

Michael Young's The Rise of the Meritocracy has attracted a mixed reception over the years and has variously been taken to be for, against or ambivalent towards a society being ordered along the meritocratic principles it spells out. ${ }^{1}$ The text can and has been read as supporting all of these positions. Young was advocating the desirability of removing hereditary privilege as the basis for social order and (with echoes of Plato's Republic) promoting the efficiency and justice of a division of labour based upon mobility of individual talent and effort, or 'merit'. He was also alerting us to the danger that if taken too far, a fully evolved meritocracy would be based on a brand of positivism that smothered human values and decency, and (with echoes of Orwell's Animal Farm) would crystallise into a smug and self-replicating elite class or oligarchy that would pull the ladder of opportunity up behind it, and hence no longer be a true meritocracy of talent.

Life can sometimes be stranger than social science fiction, and in later years Young looked on while within the political realm his 'meritocracy' was shaping up to become its own antithesis, located at the heart of modern democratic thought. In his BBC obituary, Young's invention is placed 'at the centre of Blairite thinking', ${ }^{2}$ although six months earlier he had publicly reclaimed his concept, stating 'It would help if Mr Blair would drop the word from his public vocabulary' and 'he [Blair] has caught on to the word without realising the dangers of what he is advocating'. ${ }^{3}$ Young had, however, long recognised that Meritocracy was largely misunderstood and that the idea of 'meritocracy' had taken on a life of its own independent from his original, albeit mixed, intention.

But why was this so? Referring to both political and academic spheres, Young speculates that Meritocracy is an influential book, that the most influential books are those that are not read', that people have commented upon or referred to his text without ever having read it, and that most of these people have not recognised the text as satirical. ${ }^{4}$ This chapter takes up his challenge and reviews the political science serial literature from 1958 onwards that cites Meritocracy, to investigate whether there is 'citation without knowledge' and if the text has been properly recognised as satire. The chapter then goes on to study the career of the 'meritocracy' concept and the various pathways it has taken in political science papers that do and do not refer to his original work. ${ }^{5}$

(C) 2006 The Author. Editorial organisation (C) 2006 The Political Quarterly Publishing Co. Ltd 


\section{How the text is presented}

The full title of Young's work ${ }^{6}$ is The Rise of the Meritocracy, 1870-2033: an Essay on Education and Equality, and it is presented as a $\mathrm{PhD}$ thesis in British historical sociology, written by a fictional Michael Young in either the year 2033 or 2034. The mock futuristic PhD was, to say the least, an unorthodox choice of format, which proved to be so problematic that Young (whose alter ego was in this instance literally ahead of his time) feared his manuscript would never be published. Chatto and Windus, who Young describes as 'an old, respected, and literary English publisher', were prepared to publish the work if it was rewritten as a novel in the style of Aldous Huxley's Brave New World. This Young dutifully did, 'with the young and ravishing Lady Avocet as the heroine having a love affair with an elderly plumber'. Needless to say (and probably mercifully on the grounds of crimes against literature), this version did not appear in print. Another publisher, Longman, somewhat missed the point and rejected Young's original text on the grounds that they did not publish PhD theses, an event Young describes as 'fair warning that the book, if it ever did see the light of day, was going to be misunderstood'.

The manuscript was rejected by eleven publishers, but eventually went to print due to a chance meeting on a beach in North Wales and the kindness of an old friend of Young's, Walter Neurath, who, with his wife Eva, had founded the publishing house Thames \& Hudson. The book first appeared in 1958, and shortly afterwards was reproduced by Penguin and became a bestseller, appearing in seven languages.

Although later editions lost the full original title, when handling the book it is very clear that this is a satire, or what we might call a 'social science fiction'. On the first page of the text proper, we are told that the Populist Movement has called for a general strike in the coming May of 2034, and that there has been wide-scale civil revolt, including spates of unofficial strike action, the 'gutting' of the Ministry of Education and even the destruction of an atomic power station. ${ }^{9}$ On the last page of the book, a footnote tells us that Michael Young was killed in the Peterloo riots of May 2034, and that the publishers have left his thesis unaltered, although 'The failings of sociology are as illuminating as its successes ${ }^{\prime 10}-\mathrm{a}$ hint that the fictional Michael Young's account of the meritocracy should be taken with a pinch of salt. Given that his misreading of the social and political situation cost him his life, it is doubtful that on the strength of his analysis the pretend Michael Young would have been awarded his doctorate posthumously.

The book is divided into two parts. The first, 'Rise of the Elite', gives a largely historical materialist account of the conditions that led to the shift in British society from agrarian feudalism to industrialism to a meritocracy, a change driven by the increasing demands of international competition to maximise the efficiency of the whole workforce. It also describes the decisive role that the Labour Movement played in securing the transition to a meritocracy through its pursuit of policies aimed at promoting equality of 
opportunity and eradicating hereditary privilege. We are introduced to the formula I $+\mathrm{E}=\mathrm{M}$ (intelligence, or IQ, plus effort equals merit), which decides every person's station in life as educational selection becomes the rational and moral imperative upon which the meritocracy is built and sustained. ${ }^{11}$ The membership of the meritocracy is limited to the 5 per cent of the population who have the most powerful jobs, the highest status and the greatest material rewards. It is made up of those selected to receive the best education. Their elite status is earned through their own intelligence and effort, and hence merit. Those who are excluded from the elite have simply failed to make the grade although, the argument goes, their interests are best served by the meritocracy, as this is the most efficient use of the country's talent in the arena of international competition and the benefits from this flow to all.

The tone in this first section is largely positive, praising the creation of the meritocracy as the basis of the social order rather than heredity, but the mood becomes increasingly menacing in the author's mounting contempt for those who fall outside of the elite, eroding our faith in his academic neutrality. As we would expect of a thesis, there are many footnotes, and these largely refer to genuine government reports and academic texts.

The second half of the text, 'Decline of the Lower Classes', is the larger projection into the future, where we encounter the undesirable aspects of a fully fledged meritocracy, and the author is unmasked as an intolerant voice, who holds the grievances of the masses in increasing contempt as he defends the interests of the elite of which he is a part. In this dystopic vision, the working class is stripped of its articulate potential leaders, the trade unions come to represent elite interests, domestic service is reintroduced, the meritocracy becomes anti-democratic as Parliament is weakened by the rule of the Civil Service, and ultimately the meritocracy itself becomes a closed self-replicating elite, which has pulled up the ladder of opportunity behind it. Some of the references in this section are genuine and largely Fabian in orientation, but most are inventions (for some unknown reason, there is a preponderance of bird names in phoney citations; for example, Dr Nightingale, Dr Puffin, Professor Eagle, Rook, Stork and Shag), and Young even invents an 'interesting' reference to himself in a 1967 British Journal of Sociology paper, 'The role of the extended family in channeling aspirations ${ }^{12}$ - Note the earliness of the date,' he says. ${ }^{13}$

The book is also peppered with various flights of fancy, and we are witness to numerous futuristic inventions, some more prophetic than others, such as the invention in Britain of a Social Science Research Council—which was actually created in 1965, with Young as its first chair. However, he was less successful in predicting that milk would be on tap in every home, that in the 1990s Chinese would become the second language in schools and, most outlandish of all, that sociology is a highly respected enterprise. Of course, the most enduring of Young's inventions is that of the 'meritocracy' itself, which makes its first outing in this book. If the interested reader was eager to trace the original source of this concept, he or she would find the following in an early footnote: 
The origin of this unpleasant term, like that of 'equality of opportunity', is still obscure. It seems to have been first generally used in the sixties of the last century in small-circulation journals attached to the Labour Party, and gained wider currency later on. ${ }^{14}$

Here Young is teasing himself, and the reader. Until 2034, the jury is of course out on whether Young's vision of a meritocracy as a calcified regime will come to pass, although in his later opinion he felt that it was already taking shape in Britain at least. ${ }^{15}$

In any case, it is very difficult to see how Meritocracy can be mistaken for a standard academic text.

\section{The satire}

In a new introduction to the Transaction edition, the real Michael Young mulls over how his book was received and how his invention 'meritocracy' has been used. He cites Daniel Bell's view that the logical form of a postindustrial society is that of a meritocracy, where differential status and income are tied to technical expertise and higher education, which generally excludes people without the relevant educational qualifications. ${ }^{16}$ Young holds that Meritocracy was 'always meant to make that kind of case' and that, for whatever reason, most people have 'accepted that must have been the case I was trying to make'. ${ }^{17}$ What we may call the utopian version of meritocracy, presented in the first half of his book, is founded upon the principle of equality of opportunity, and embodies the $\mathrm{I}+\mathrm{E}=\mathrm{M}$ formula, where following educational selection (or I) people are allotted different roles in society, and those who enter the higher echelons must continue to be high achievers (or E) to deserve (or M) the benefits and material trappings that belong to the elite. Another premise is that of absolute mobility, to ensure that each generation will continue to be educated, employed and rewarded according to achievement or talent and not birth. However, while this was part of Young's intention, those who believe that he was presenting a utopian meritocracy have not, in his view, correctly interpreted his text:

They have neglected, or not noticed, the fact that the book is satirical, and although sociology, and therefore properly earnest, it is also in an older tradition of English satire. I know that in those island clothes the book may not travel so well. But if the book is not seen to be counterargument as well as argument, the point of it (or at least a good half point) will be lost. ${ }^{18}$

In Young's words, 'Another line of argument is also made much of in the book. It is that a meritocracy could only exist in any full form if there were such a narrowing down of values that people could be put into rank order of worth. ${ }^{19}$ He evokes the work of John Rawls to describe the counterargument in the second part of his book, which we may call the dystopian version of meritocracy. Rawls recognised that equality of opportunity could eventually lead to a 'callous meritocratic society'. ${ }^{20}$ 
Young explains that as a satire, his book was meant to argue both sides of the case for and against a meritocracy: 'The two points of view are contrasted without. The imaginary author has a shadow. ${ }^{21} \mathrm{He}$ continues:

The imaginary Michael Young of 2034 is meant to seem more dour and portentous than I am. I am, by apparently taking his views so seriously, trying to make fun of him. . . . I tried to make him out rather ridiculous because I also wanted to show the strength of the opposite case. I wanted to show how overweening a meritocracy could be, and, indeed, people generally who thought they belonged to it, including the author to whom the book was attributed. ${ }^{22}$

Young's alter ego was unwittingly 'the mouthpiece for another story, showing how sad, and fragile, a meritocratic society could be'. ${ }^{23}$ We must, however, be aware of a further twist - that when academics cite the Michael Young of The Rise of the Meritocracy they are in fact using the words of his often misanthropic doppelganger.

\section{The tests}

\section{Young's citation challenge}

Past research has demonstrated that texts may be referred to without apparent knowledge of their content, and has even shown that some social scientists have referred to 'classic' or foundational works incorrectly. ${ }^{24}$ Young himself takes this argument one step further. Observing that Meritocracy is an influential book, he makes the bold assertion that 'the most influential books are those that are not read', that people have commented upon or referred to Meritocracy without ever having read it, and that most of these people have not recognised the text as satirical ${ }^{25}$ but only as the utopian version of the meritocracy presented in the first part of the book. This chapter tests Young's retrospective hypotheses in the form of a citation and content analysis to examine (a) whether people who comment upon the text have read it, and (b) if they recognise or make reference to the fact that the text is satirical.

\section{Obliteration}

The idea of 'obliteration' refers to work presented in original sources or foundational texts that ceases to be cited because the concepts or methods eventually become absorbed into the assumed knowledge of a field. This chapter goes beyond Young's hypotheses to examine whether the intended spirit of Meritocracy has survived over time. It examines papers that discuss meritocracy, but do not cite the original work, to test the prevalence of utopian, dystopian or other versions. 


\section{The fictitious formula}

Young realised that 'there was nothing new in the proposition that $\mathrm{IQ}+$ effort = merit; only the way it was formulated', ${ }^{26}$ although he was lampooning the idea that these combined factors, whether brought about by nurture, nature or a combination of both, could produce a moral imperative:

Even if it could be demonstrated that ordinary people had less native ability than those selected for high position, that would not mean they deserved to get less. Being a member of the 'lucky sperm club' confers no moral right to advantage. What one is born with, or without, is not of one's own doing. ${ }^{27}$

This chapter investigates whether this fictitious formula (in the form of $\mathrm{I}+\mathrm{E}$ $=\mathrm{M}$, or $\mathrm{IQ}+\mathrm{E}=\mathrm{M}$ ) has been taken seriously as a measure and has gained any currency. The content analysis scans all papers for the inclusion and use of this equation, as a further test of whether the text has been read and understood as satirical.

\section{The methods}

A sample of political science papers ${ }^{28}$ is taken from the Institute of Scientific Information's (ISI's) Web of Knowledge v.3.0. ${ }^{29}$ This online resource provides detailed information on indexed serial literature in the form of journal papers, reviews and other contributions. For the social sciences, the Social Science Citation Index covers 1,725 journals from 1945 onwards. While the sample is limited to journals rather than books, references to books can be traced through the bibliographies of ISI-indexed papers.

\section{Citations to The Rise of the Meritocracy (testing Young's citation challenge)}

The bibliographies of texts therefore allow us to identify which papers cite Young's work. Combinations of Cited Work searches were conducted, combining the Science Citation Index (SCI), the Social Science Citation Index (SSCI) and the Arts and Humanities Citation Index (A\&HCI) for all available years, and 283 citing texts were found:

$\begin{array}{lr}\text { RISE OF MERIT }^{*} & 1 \\ \text { RISE MERIT }^{*} & 275 \\ \text { MERIT }^{*} & 7\end{array}$

Non-English-language papers were filtered out, leaving a total of 261 texts. Of these, 14 (5.4 per cent) were political science publications, following sociology (24.1 per cent), education and educational research (20.3 per cent), social sciences, interdisciplinary topics (7.7 per cent) and law (6.9 per cent). ${ }^{30}$ Ten of the political science texts were classified as articles, and four as reviews. The distribution of years of publication is as follows: 


\begin{tabular}{lcc}
\hline Publication year & Record count & Per cent \\
\hline 1959 & 1 & 7.1 \\
1960 & 1 & 7.1 \\
1973 & 4 & 28.6 \\
1975 & 4 & 7.1 \\
1976 & 2 & 14.3 \\
1977 & 1 & 7.1 \\
1980 & 1 & 7.1 \\
1982 & 1 & 7.1 \\
1993 & 1 & 7.1 \\
1998 & 1 & 7.1 \\
\hline
\end{tabular}

Content analysis was then applied to these texts to give yes-or-no answers to the following questions:

1. Are sections of The Rise of the Meritocracy quoted, or does the text demonstrate enough knowledge of the work for us to assume that it has been read?

2. Is The Rise of the Meritocracy understood as dystopic/satirical?

3. Is the sampled text for or against the idea of a meritocracy?

\section{Use of the concept of 'meritocracy' (testing for obliteration)}

It is possible to search the titles, keywords and abstracts of ISI-indexed journals for particular words. It is important to note that ISI only holds data on keywords from 1992 onwards, and abstracts from 1993 onwards. This will affect the distribution of papers in the sample. Again, all three ISI indexes were used for all available years, using General Search: Topic: MERITOC*, and 268 texts were identified. Works that cite Meritocracy were excluded from this sample, leaving 229 papers, and non-English-language papers were removed, giving a total of 207. Of these, 15 (7.2 per cent) were political science publications, with sociology (22.2 per cent) and education and educational research (17.4 per cent) being dominant. Eight of the political science papers are classed as articles, six as reviews and one as editorial material. The years of publication are as follows:

\begin{tabular}{lcc}
\hline Publication year & Record count & Per cent \\
\hline 1987 & 2 & 13.3 \\
1993 & 1 & 6.7 \\
1995 & 1 & 6.7 \\
1999 & 6 & 40.0 \\
2000 & 2 & 13.3 \\
2001 & 1 & 6.7 \\
2003 & 2 & 13.3 \\
\hline
\end{tabular}


Content analysis was used to answer the following questions:

1. Is the concept of 'meritocracy' defined, and if so, is it utopian or dystopic?

2. If the concept of 'meritocracy' is not defined, can we infer that it is viewed as utopian or dystopic?

3. Is the sampled text for or against the idea of a meritocracy?

$$
I+E=M \text { (using the fictitious formula) }
$$

All papers were scanned to see if this formula had been used or discussed as a substantive measure, and if so, within what kind of context.

\section{Results}

\section{Testing Young's citation challenge}

Even using primitive analysis, we find various points of discussion about the political science texts that cite Meritocracy. Most use was made of the book in the mid-1970s, reflecting an interest in debates about distributive justice, its first standard use being fifteen years after its original publication. There are two reviews of Young's book, and I am happy to report that both reviewers have clearly read the text and have understood it as satire. There are two reviews of other books and these cite Meritocracy: a 1973 review of Rawls' A Theory of Justice, and a 1998 critique of Noberto Bobbio's Left and Right. The remaining ten works are standard journal papers. It is somewhat surprising to find that, with one exception, all the political science papers originate from the United States, the one exception being the Briton Perry Anderson, who was then resident in Italy:

\begin{tabular}{rrlllll}
\hline Paper & Year & Type & $\begin{array}{l}\text { Quoted/ } \\
\text { read? }\end{array}$ & $\begin{array}{l}\text { Dystopic/ } \\
\text { satirical? }\end{array}$ & $\begin{array}{l}\text { For or against } \\
\text { 'meritocracy'? }\end{array}$ & Country \\
\hline 1 & 1959 & Book review & Y & Y & Against & US \\
2 & 1960 & Book review & Y & Y & - & US \\
3 & 1973 & Article & & Y & Against & US \\
4 & 1973 & Article & & Y & - & US \\
5 & 1973 & Article & Y & & For & US \\
6 & 1973 & Article & & Y & Against & US \\
7 & 1975 & Book review & N & N & - & US \\
8 & 1976 & Article & Y & N & - & US \\
9 & 1976 & Article & & Y & - & US \\
10 & 1977 & Article & & N & Against & US \\
11 & 1980 & Article & & Y & Against & US \\
12 & 1982 & Article & N & N & Against & US \\
13 & 1993 & Article & Y & Y & Against & US \\
14 & 1998 & Book review & N & Y & Against & Italy \\
\hline
\end{tabular}




\begin{tabular}{|c|c|c|c|c|c|}
\hline \multicolumn{2}{|c|}{ Quoted/read } & \multicolumn{2}{|c|}{ Dystopic/satirical } & \multicolumn{2}{|c|}{ For or against 'meritocracy' } \\
\hline Yes & No & Yes & No & For & Against \\
\hline 5 & 3 & 9 & 4 & 1 & 8 \\
\hline
\end{tabular}

We find that three texts that cite Meritocracy display no evidence of the writer having read it. One is the review of Rawls, which just mentions Young's book in a footnote; another review refers to Meritocracy in passing; and one article merely speaks of Young's book in the same breath as a serious 1967 book chapter by another author, as 'two particularly valuable contemporary criticisms of the ideal of meritocracy'. The writers of five texts have either cited from or have clearly read the book, two being reviews of it. The article that displays the most comprehensive understanding of Young's book is a critique of liberal notions of distributive justice, and invents the ironic term 'Neo-Youngian' for the argument that those people who are socially excluded in terms of having no access to goods through distributive processes are in that situation due to their own apathy or incapacity. However, two papers that cite Young appear to have missed the point, one using Young to talk of the Civil Service as a 'true meritocracy of talent', while the other cites the Populist Movement's Chelsea Manifesto, which sets out a more humanistic way in which to value people, but does not indicate that this was held in sharp relief to the values of the meritocracy. Of the five authors who cite the book, only three appear to have really understood it in Young's terms.

Four texts demonstrate no understanding that Young's book is satirical. One displays no evidence of the writer having read the book, yet goes on to argue that Young extrapolates from documented trends in British education to argue 'that this theory of equal opportunity justifies a continuation of the British class system or a version of it'. The writer of one paper, who displays no evidence of having read Young's book, nonetheless has sufficient knowledge to make a jibe at two highly statistical advocates of meritocracy, noting that 'one of the most charming things . . . is that they don't know Young's book is a satire'.

In terms of testing Young's hypothesis, we find that just three out of the fourteen papers demonstrate the authors have both read his book and understood his intent. However, five that seem not to have read the book nonetheless understand its import. Overall, nine texts recognise Young's book as dystopic or satirical, and eight are clearly against the idea of a meritocracy. There is a decay effect as citations to Young's book-or evidence that an author has sufficient familiarity with the book-ebb, along with the understanding that the work is satirical. However, this contrasts with a trend towards being more critical of a meritocracy. In short, Young's hypothesis stands, and his intent seems to have been successfully transmitted. 


\section{Pathways of 'meritocracy'}

The journal texts that use meritocracy in their title, abstract or as a keyword, but do not cite The Rise of the Meritocracy, are published between 1987 and 2003. It was noted above that ISI only lists keywords from 1992 onwards, and searches abstracts from the year 1993, and this impacts upon the distribution of papers, as any earlier papers that discuss meritocracy may be missed. There is increased interest in this area post-1999, and although this is largely due to five reviews of one particular book, Nicholas Lemann's The Big Test: the Secret History of the American Meritocracy, there are also six full journal papers. There was one further review in 1987, and one editorial piece that also includes an interview. There are eight full papers in total:

\begin{tabular}{|c|c|c|c|c|c|c|}
\hline Paper & Year & Type & $\begin{array}{l}\text { Defined/ } \\
\text { inferred }\end{array}$ & $\begin{array}{l}\text { Utopian/ } \\
\text { dystopian }\end{array}$ & $\begin{array}{l}\text { For or against } \\
\text { 'meritocracy'? }\end{array}$ & Country \\
\hline 15 & 1987 & Book review & $\mathrm{D}$ & Dystopian & & US \\
\hline 16 & 1987 & $\begin{array}{l}\text { Editorial/ } \\
\text { interview }\end{array}$ & $\mathrm{I}$ & \multicolumn{2}{|l|}{ Dystopian } & US \\
\hline 17 & 1993 & Article & $\mathrm{D}$ & \multicolumn{2}{|l|}{ Utopian } & US \\
\hline 18 & 1995 & Article & $\mathrm{I}$ & Utopian & & US \\
\hline 19 & 1999 & Article & $\mathrm{I}$ & Utopian & For & US \\
\hline 20 & 1999 & Book review & $\mathrm{D}$ & Both & For & US \\
\hline 21 & 1999 & Book review & $\mathrm{D}$ & Dystopian & Against & US \\
\hline 22 & 1999 & Article & & & & US \\
\hline 23 & 1999 & \multirow{2}{*}{$\begin{array}{l}\text { Book review } \\
\text { Article }\end{array}$} & $\mathrm{D}$ & \multicolumn{2}{|l|}{ Dystopian } & US \\
\hline 24 & 1999 & & & & & US \\
\hline 25 & 2000 & Book review & $\mathrm{D}$ & Utopian & Against & US \\
\hline 26 & 2000 & \multirow{2}{*}{ Book review } & $\mathrm{D}$ & Utopian & Against & US \\
\hline 27 & 2001 & & D & Utopian & & US \\
\hline 28 & 2003 & Article & $\mathrm{D}$ & Both & For & US \\
\hline 29 & 2003 & Article & & & Against & Canada \\
\hline \multicolumn{3}{|c|}{ Defined/inferred } & \multicolumn{2}{|l|}{ Type } & \multicolumn{2}{|c|}{ For or against 'meritocracy' } \\
\hline Yes & \multicolumn{2}{|c|}{ No } & Dystopic & Both & For & Against \\
\hline 12 & \multicolumn{2}{|c|}{3} & 4 & 2 & 3 & 4 \\
\hline
\end{tabular}

Again, we find that the texts are almost exclusively American, the exception being one Canadian article. It is remarkable to note that two articles have 'meritocracy' in their title (they are coupled together as a 'for and against' piece) but neither of them mentions meritocracy.

Nine of the offerings do set down what they take meritocracy to mean: five subscribe to the utopian version, three to the dystopic reading and two employ both. We are able to infer the type of 'meritocracy' used in a further 
three further papers, one of which is dystopic and two utopian. So in total six papers subscribe to the utopian reading and four share Young's cynicism, while two discuss both views but identify with neither. The utopian reading coincides with liberal notions of distributive justice, and we find that two of these papers use this definition, but are opposed to this kind of meritocracy. In short, we find that there is almost equally divided opinion about the meaning of the term and those who are for and against the idea of a meritocracy. In this sense, although not cited, the two parts of Young's book are alive and well, and still shadowing each other.

For example, versions of the utopian meritocracy include defining the 'level of meritocracy' as 'the degree to which individual merit is a factor in determining economic outcomes'; arguing that 'educational expansion is critical for signalling modern ideas of mass opportunity and meritocracy'; and the assessment that 'America is likely to retain strong meritocratic tendencies' and to continue heavily using intelligence testing because 'People believe in it. Institutions are used to it. And most importantly, even as we recognize that testing has its drawbacks and limitations, the alternatives are either impractical, undesirable, or worse.' The utopian vision sees meritocracy as going hand in hand with democracy. On the other hand, the dystopic readings include seeing meritocracy as 'the classic dilemma facing all democratically-inclined societies' in the form of 'how to select, on the basis of merit, a sufficient cadre of leaders of all types required to move society forward, without ending up with a self-servicing and self-perpetuating elite that dominates the rest of society'; and arguing that governments use a 'meritocratic veneer' to say that institutions promote equal opportunities, while they instead promote systemic structured economic inequalities; and although not cited in the bibliography, Young is correctly remembered when one author notes that "The phrase "meritocracy" came from Michael Young... who worried that the new educated ruling elite would have so powerful a basis of legitimacy as to make inequality even harder to reduce.' The dystopic version of meritocracy is concerned that it is ultimately unjust and can be antidemocratic.

It is interesting to observe that new forms of 'meritocracy' are being invented. For example, Lemann's book talks of 'real meritocracy', echoing the Chelsea Manifesto by arguing for the concept of merit to be expanded to include qualities such as 'wisdom, originality, humor, toughness, common sense, independence, determination'. In sharp contrast, one mathematically inclined paper talks of 'no-meritocracy' (where merit determines no outcomes), 'low-meritocracy' (where merit determines outcomes 10 per cent of the time), moderate or ambiguous meritocracy (50 per cent), and the 'perfect meritocracy condition', where 'those who choose to work hard always prosper'. But however meritocracy is formulated, we find that Young's original argument and counterargument remain dominant and are still in conflict. 
$I+E=M$ (using the fictitious formula)

None of the political science papers use this equation, although some do talk about it in longhand. In the political science case study, there is therefore no evidence that this equation has gained any currency as a serious measure.

\section{Conclusion}

This review of the political science serial literature has been very successful in testing Young's retrospective hypothesis, which is found to be positive. The content analysis has also been a valuable device for tracing how the use of the term 'meritocracy' has evolved and taken on a life and a meaning that is divorced from Young's original contradictory intent, although the spirit of ambiguity embedded in The Rise of the Meritocracy still thrives. Young created a dual tension between the utopian and dystopian visions of meritocracy, which act to counterbalance each other within the original text, but inside the political science literature there has been a tendency for this tie to snap and the utopian and dystopian versions have taken separate journeys. ${ }^{31}$ Various 'narratives' for and against meritocracy emerge and, noting the influence of other books, perhaps counter-intuitively, those who cite Rawls are more likely to be against the idea of a meritocracy than those who cite Bell.

To sum up, Young's challenge has been vindicated. We can also see that there has been a dualism in the subsequent intellectual development of his concept of meritocracy, although the satirist in him, rather then the social democrat, would perhaps have approved of this. To use his own words, the decision for or against the meritocracy is one that he 'left to the reader, the hope being that, on the way to making up his or her mind on one of the great issues of modern society, he or she will also have a little fun'. ${ }^{32}$ 